larger vessel with about 500 c.c. of absolute alcohol, and as
much absolute ether as was required to aritate the mixture much absolute ether as was required to agitate the mixture
strongly, when all the hypophosphite separated. The salt
was collected and deprived of the last traces of alcohol and was collected and deprived of the last traces of alcohol and
ether by passing over it a current of dry air.
The ethereo-alcoholic liquid, after the separation of the The ethereo-alcoholic liquid, after the separation of the
salt, was completely neutral. The hypophosphite, crystallized in small needles, dissolved perfectly in water and in
alcohol, and the solntion was not rendered turbid by the addition of baryta or sulphate of soda. Once only it contained a trace of sulphuric acid, consequent upoc the employment DECOMPOSITION OF CHLORINE.

Yr. FRED'k Barkas, of the Zurich Polytechnikum, "A most important chemical discovery has just been
made by Herren Victor and Carl Meyer, of the Polytechnikum, Zurich. Herr Victor Mever had been making a num. organic compounds whose constituents were doubtful. Hav-
in. invented a new and simple apparalus for the purpose, in $t$ ) test the vapor density of the commoner elements - oxygen
or t) thest the vapor density of the commoner elements-oxygen,
etc. - at temperatures fiom $100^{\circ} \mathrm{C}$. (boiling water) to $1,567^{\circ} \mathrm{C}$.
(h-at given by a gas furnace). At length be tried chlorine, which was obtained by heating pure dry bichloride of platinum, but the results were not in accordance with theory.
When the gas was heated at temperatures under and up to $6^{2} 0^{\circ} \mathrm{C}$. it gave a density of $2 \cdot 46$, while theory gives $2 \cdot 45$.
This was very good ; but at $808^{\circ} \mathrm{C}$. the density was only $2 \cdot 20$. At 1,028 C. it gave 1.87 , while at from $1,242^{\circ} \mathrm{C}$. to $1,567^{\circ} \mathrm{C}$. the density remained nearly constant at 1.64 average. From
this it was to be inferred that t wo molecules of clilorine at this it was to be inferred that two molecules of chlorine at
temperatures above $1,200^{\circ} \mathrm{C}$. breakup into the three mole cules.
Next came the question, Does this arise from an alteration of the molecular constitution of chlorine, or from an actua rine an element? Thereupon the expanded chlorine gas was
slowly caused to stream into al fluid tbat absorbs chlorine. Potassa, iodide of potassiu m, and mercury were all used $\mathrm{for}$ the purpose, and with the same result-a gas accumulated
in the measuring tube that was not chlorine, but oxygen Chlorine was thereby proved to be not an element but an
oxide of some new element. A number of careful investi. gations were then nade to be sure that the chlorine used was absolutely pure and dry, but with the same result. The new elenient, hypothetically called Murium, has not yet been
isolated, but the learned professors are carrying out the important investigation with all diligence, so that doubtless
within the course of a few weeks we shall hear more of the new element, Muriem. That chlorine is an oxygen com
pound is not altogether a new idea. Sir Humphry Davy pound is not altogether a new idea.
after his celebrated discoveries of the compound nature of
soda and potassa, surmised that chlorine, iodine, and bromine were likewise oxygen compounds.

SPECIFIC HEATS AND MELTING POINTS OF
VARIOUS REFRAC'TORY METALS. By J. Violle.

THe specitic lieat of iridium, like that of platinum, in heat of gold varies little up to $600^{\circ}$, and then increases sensibly on approaching the melting point. The melting points
given are: Silver, $954^{\circ}$; gold, $1,035^{\circ}$; copper, $1,054^{\circ}$; palla-
dium, $1,506^{\circ}$; platinum, $1,775^{\circ}$; iridium, $1,950^{\circ}$. CEJ JLULOSE.

By M. Franchimon

THE author adds to a mixture of 1 part of cellulose and 4 reaction is set up and the cellulose disappears; whilst the liquid becomes colored. The whole is then thrown into a
larye excess of cold water, which gives a copious white pre-
cipltate. The precipitate is washed in cold water and dried in the air, and is next introduc $: d$ into alcohol, which dissolves $\&$ part and turns slightlly yellow. It is filtered, washed
in alcobol, and the residue dissolved in boiling alcohol. The It seems to be an eleven times acetylated derivative of
triglucose, $\mathrm{C}_{18} \mathrm{H}_{32} \mathrm{O}$ is.

\section{CHLORIDE OF LIME BATTERY.}

By $A$. NiaddeT.

THE battery has for its positive electrode a plate of zinc, and for its negative electrode a plate of coke surrounded
with fragments of coke. The zinc is placed in a solution of common salt; the coke is strrounded with chloride of lime Non-Porbonods VEGETABLE FLy PAPER AND RAT Ex-
TERMiNATOR. - Reisenbichler calls attention to the fact that
the poisonous preparations employed for the destruction of vermin could easily be replaced in the market by others
equally effective and altogether free from danger. He sug. gests for the destruction of flies porous paper spread with a mixture of sirup and pulverized black pepper, the latter
being a deadly poison for flies. When used it requires simply to be moistened and spread on a plate. For rats, be
recommends squills, cut into cubes, then thorougbly dried and pulverized, and made into brittle, porous cakes, from starch added. When used they need simply be saturate TEST For Colorisg MatTer IN RED W INE-Sulzer has
found that on mixing an equal volume of nitric acid with a
sample of the wine to be tested, the color if natural will remain unchanged for at least an hour, whilst if artificial it will be discharged, or changed within a minute. The re.
action has been found to take place with the coloring mat.
ter of whortleberries, mulberries, mallows, logwood, Brazilter of whortleberries, mulberries, mallows, logwood, Brazilcid and fuchsine.

Melting Asphaltom. - The burning of the film adhering to the sides of the kettle in melting asphaltum and prevent, may be avoided, according to Reisenbichler, by
melting on a bath of concentrated solution of chloride of calcium in water. As this boils at about $358^{\circ}$, a uniform
high temperature may be obtained.
THE AFRICAN CABLE.

THE great African cable is the longest in the world, it being
4,000 miles from Aden to Natal; but for the convenince of working, as well as to facilitate any necessary repairs, 350 miles-from Durban, in Natal, to Lorenzo Marquez, at Delagoa Bay - has been laid, as also has the second section,
from the bay to Mozambique, a distance of 1,000 miles; and very recently the line from Mozambique to Zanzibar was
finished. Thus the fullest details of all that is passing in finished. Thus the fullest details of all that is passing in
South Africa will be forwarded to that station and carried on over the last and longest section to Aden, where it will of 2,000 miles in length, will not be completely in working order till the middle of December, but in the meantime, we
believe, it is the intention of the government to place one or more fast dispatch boats at Zanzibar to forward all import-
ant intelligence; and if this is done we ought to have fre. quent dispatches only three or four days old. Except the las sight of the bigh lands of Africa. The minimum rate at ords a minute. But the tendency of all calles when sub-
outh merged is to improve so rapidly, that at a rate of at least hour, is likely to be soon attained. This would give nearly
wo-thirds of a neivspaper column ner hour, or sixtee newspaper columns in the twenty.four, as, of course, it would work day and night. With the completion of this
link the last of the great imperial dependencies will be
placed in direct communication with England, and the experience of the working of all previnus lines shows the
lmost inestimable value, both to colonies and crown, of such a swift and secret means of the fullest and most con-
suld fidential inter euurse. The government, of course, have a sages can be sent with less than one-quarter of the signs.
and, therefore, in less than one-quarter of the time required or the ordinary signals. By and-by the warlike news of the cable will settle down into commercial items-ex.
changes, prices of wool, ivory, skins, ostrich feathers, and

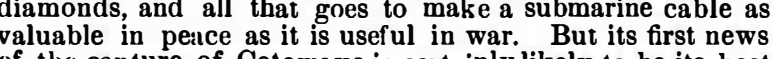
of the capture of Cete

\section{$\Lambda$ NICKEL BATTERY}

AN improvement in galvanic batteries, recently pateuted
y in such a mauner that the salts of that metal produced by he action of the battery are of commercial value, and in the
arrangement of the elements in such a manner that the cells
are of the "perfluent" type, by which the battery is kept in

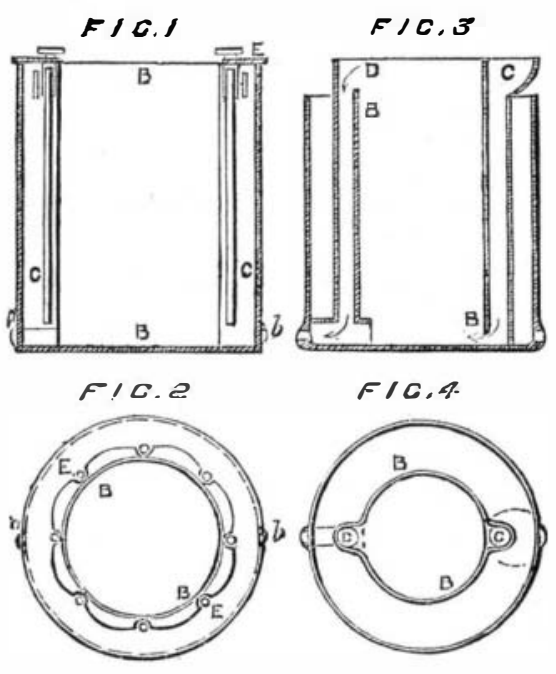

continuous operation. The invention, which admits of many modifications, may be thus described:
Witl a cell of two metals in two liquids the patentee predrical plate of nickel which may be crimped, grooved, furrowed, or corrugated; or nickel in grains in those cases
where the diapliragm is round or cylindrical; and where the same is square or oblong, by preference flat plates. Sur rounding the nickel cell, he places any suitable or desired
number, according to the size of the vessels, of narrow prisms or plates of carbon placed not more than a quarter of an inch apart in urder to obtain the best cffect, though any
less number or a single prism, or plate, or cylinder will
work, but not so efficiently.

and to insure good connection plates surround the nickel cell, better to have a clamp of metal with a projecting part, pin, holes corresponding to the number of prisms or plate clamps,
made to fit thereon, and with suitable heads to the clamp,
the whole may be firmly and securely tightened and easily removed for cleaning when necessary to do so. This ring or part will be varied in shape and dimensions accord-
ing to the form and size of the cell in or with which it is to otherwise suitably formed to hold them, but the electrolyte very soon reaches the metal, oxidizes the same, and the re
sistance offered to the current is considerable. A compound ell arranged as follows may also be used:

First a cylindrical or other suitably shaped vessel or outer outer being about half an inch larger in diameter than the nickel with its excitant, which may consist of diluted sulphuric, nitric, or hydrochloric acid in the proportion of stronger or weaker proportion, as may be deemed expedient
for the work to be done. The larger diaphragms are filled in with a solution of sesqui-carbonate of ammonia, and i the outer vessel is placed a solution of sulphate of nickel, or
the double sulphate of nickel and ammonia with the prism or plates of carbon, or such metal as will receive the deposit of the metallic nickel as it becomes precipitated from its
solution, in the same way as the well-known Daniell battery precipitates the enpper from its sulphate. In order thit the lattery may be kept in continuous ope-
ation, and the sirenth of the excitant more easily be kept up, the patentee arranges it in the following manner: $\mathrm{He}$ or reservoir (to contain the exciting fluid), from which the
plath air is exhausted by a pump or other convenient means when filling the same; here is an adjustable outlet, and proper
means for leading the excitant to the cells. From the vessel n which the cells are placed is also an outlet leading into
n essel placed beneath the stand into which the excitant may ow from the battery. From this vessel a pipe of India rubto the upper one so as to keep up the supply; and in order
hat the partially exhausted excitant may have its strength restored before returning to and passing from the upperves-
sel to the battery, the required amount of acid is added to the contents of the lower vessel previous to pumping it to the contents of the lower vessel previous to pumping it to
the one, and thus by properly adjusting the outlets the battery is kept in con

Fig. 1 represents in sectional elevation, and Fig. 2 in plan, an arrangement of the improved nickel battery used with a

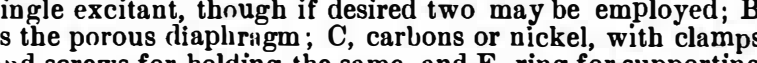
and screws for bolding the same, and $\mathrm{E}$, ring for supporting from; A is the outlet from the inner cell; and $B$, the outle
from the cuter cell ; but either of the arrangements for the "perfluent" battery may be applied to this if desired. In
Fig. 2 the outer vessel is indicated by the dotted lines, and the clamps are not slown supported by the ring, only the holes in which they fit. Fig. 3 shows in sectional cleva tion,
and Fig. 4 in plan, an arrangement of the Improved nickel and Fig. 4 in plan, an arrangement of the Improved nickel
battery, in which two excitants are to be used, although, if he emptying of the inner cell without removal, and so as to allow of its ready employment as a "perfluent" or conbeing made in one piece and the outer vessel "indurated " $n$ as to be water tight by the use of silicates or other suit-

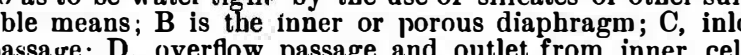
both being shown oper. The patentee has devised severa bove will sufficiently and battery arrangements, but the ure of the invention being the employment of nickel in the

ANALOGY BETWEEN THE CONDUCTIVITY FOR
HEAT AND THE INDUCTION BALANCE EFFECT

THIs was a paper recently read before the Physical SoMr. Roberts traced a remarkable resemblance between curve representing the induction balance effect of the cop-
per-tin alloys published by him in June last, and the curve
of Calvert and Johnston for the conductivity of heat, and, on the other hand, be slowed that the induction curve does not agree with Matthiessen's curve for the electric conducalloys which occupy critical points of the curve, $\mathrm{SnCu}_{3}$ and SnCu, are of much interest. Possibly both are chemical
combinations, and the wide difference in the position they occupy probably marks a difference of allotropic state. Fo sidered that we might look with coufidence to Prof.
Hughes' beautiful instrument, which, he bopes, will also ductivity for heat and electricity is really as exact as it has As supplementary to this subject, Dr. O. J. Lodge stated
that he had compared the conductivity of six bars of the tin-copper alloys, measured by the balance and by the
Wheatstone bridge, and found them to arree veryclosely on the whole. The bridge results confirmed the resemblance
traced by Mr. Roberts still more than the induction balance results.
Prof. Hughes expressed his opinion that existing tables of metal conductivity were erroneous. They disagreed among themselves, and the induction balance showed that

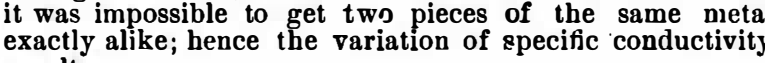
Prof. Ayrton stated that at a former meeting he had sug-

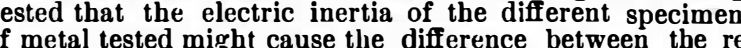
sults obtained by the Wheatsone bridge and the induction balance. Mathematical calculation had since led him to the conclusion that the inductive effect is not proportional to the resistance of the metal'tested, but'tu a poroer or exponen Prof. Hughes replied that as the inductive effect of the metal was destroyed by cutting it so as to interrupt the
circuit in it, it was reasonable to suppose that the said effect was due to induced currents circulating in the metal, and therefore was proportional to the conductivity of the Capt. Armstrong exhibited a standard Daniell cell formed of porcelain vessel with a porous partition dividing it into a solution of sulphate of zinc; in the other the copper plate in a solution of sulphate of copper. To use the cell as a standard, it was only necessary to connect the two liquids by a cotton string moistened with water. This arrangemen drawn after use. The resistance was ligh, but it was a con Prof. Guthrie mentioned that Prof. Pirani, of Melbourne, cid was being electrolyzed, the positive electrode, if made of iron, became incandescent below the surface of the liquid. Prof. Guthrie had found this to be true not only for iron, dation, because it took place not only at the cathode of ositive electrode, where oxygen was evolved, but also he anode, where hydrogen was evolved. The incande author exhibited his experimental results, which he did not

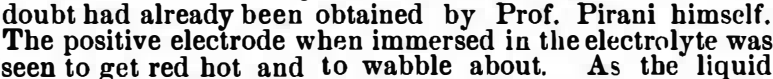
seen to get red hot and to wabble about. As the liquid heated, the red glow became fainter. The negative elec-
trode, on the other hand, emitted a bright light, accom panied by a sputtering noise. The light was tinged with it was composed; in the case of a copper electrode, for exam ple, it was greenish. These effects were shown by Prof.
Guthrie with iron, copper, and platinum electrodes, in dilute sulphuric and dilute nitric acid. In reply to Prof. Adams, Prof. Guthrie said he had not
yet examined the flame by the spectroscope; and in reply to 